\title{
Effects of Air Pollution on Disease Respiratory: Structures Lag
}

\author{
Amaury de Souza1, Yuming Guo², Hamilton Germano Pavão', Widinei Alves Fernandes ${ }^{1}$ \\ ${ }^{1}$ Institute of Physics, Federal University of Mato Grosso do Sul, Campo Grande, Brazil \\ ${ }^{2}$ School of Medicine, The University of Queensland, Brisbane, Australia \\ Email: amaury.de@uol.com.br
}

Received 15 April 2014; revised 20 May 2014; accepted 28 May 2014

Copyright (C) 2014 by authors and Scientific Research Publishing Inc. This work is licensed under the Creative Commons Attribution International License (CC BY). http://creativecommons.org/licenses/by/4.0/ (c) (i) Open Access

\begin{abstract}
Objective: Little evidence is available on the association between ozone exposure and health in Campo Grande, Brazil. In this study, we aimed to examine the effects of surface ozone concentrations $\left(\mathrm{O}_{3}\right)$ on respiratory morbidity in Campo Grande, Brazil during the period from January $1^{\text {st }}$, 2008 to December $31^{\text {st }}$, 2011. Methods: Daily data on respiratory hospital admissions, $0_{3}$, mean temperature, and relative humidity were collected at Campo Grande, Brazil. A Poisson time series model was used to examine the effects of $\mathrm{O}_{3}$ on hospital admissions, while controlling for seasonality, long-term trend, temperature and relative humidity. A distributed lag non-linear function was used for $\mathrm{O}_{3}$, temperature, and relative humidity. We examined the effects of $\mathrm{O}_{3}$ on different age groups ( 0 - 4 years, 5 - 60 years and >60 years). Results: The ozone-respiratory morbidity relationship was non-linear, with a threshold at 13 ppb (less than $25 \%$ percentile of ozone distribution). We estimated the relative risk of hospital admission at $75 \%$ percentile of $\mathrm{O}_{3}$ distribution compared with associated with $25 \%$ of percentile of $\mathrm{O}_{3}$ distribution. The $\mathrm{O}_{3}$ effect on respiratory morbidity was delayed by two days and lasted for 4 days for all age groups except people aged 5 - 60 years. Children and the elderly were much more vulnerable to ozone pollution than people aged 5 - 60 years. Conclusıons: This study suggests that ozone pollution has negative impacts on respiratory diseases in Campo Grande, Brazil. Children and the elderly were susceptible to $\mathrm{O}_{3}$ exposure. These findings should be used to develop policies for protecting people from $\mathrm{O}_{3}$ pollution.
\end{abstract}

\section{Keywords}

Air Pollution, Public Health, Respiratory Morbidity, Children, Ozone, Hospital Admission, Elerly

\section{Introduction}

Atmospheric pollution has been considered as a serious public health issue, especially with the increase of 
population living at urban locations. In Brazil, the population percentage living in cities reached $87 \%$ by 2010 and the cities of the developing world will make up $81 \%$ of urban humanity [1].

Atmospheric pollution is a hazard factor for human health, even the level of air pollution is very low. The most susceptible people to air pollution are children [2]-[4] and the elderly [5]-[8]. Many studies have reported that there are negative impacts on respiratory mortality and morbidity [2]-[4].

Surface ozone is a pollutant of growing concern in the world [9]. Children are the largest subgroup susceptible to surface ozone [10], particularly in terms of respiratory diseases [11] [12]. However, there are relatively few studies assessing the effects of ozone on children and adolescents' respiratory morbidity.

Moreover, most studies assessing the health effects of ozone levels used relatively short timescales (lags) [13]-[15]. If the effects of ozone on morbidity/mortality were delayed or lasted for a longer period, using short lags would not exactly capture the effects of ozone. The other issue is that most studies use linear function to examine the effects of ozone on morbidity/mortality. The biological manifestations of the effects of pollution on health apparently display behavior that shows a gap between the individual's exposure to pollutants. This means that the attendances/admissions observed on a particular day can be related to pollution of that day, as well as pollution observed in previous days. For a more precise definition of the model to be used, it is essential to determine a lag structure (lag) suitable. We chose to use the model distributed lags up to six days after exposure. Thus, using linear model can not reflect the true ozone-health relationship.

In this study, we aimed to explore the relationship between ozone and the respiratory hospital admissions in Campo Grande, Brazil. We also examined whether the ozone-morbidity relationship was non-linear; whether children and the elderly were more sensitive to ozone air pollution; and whether effects of ozone on morbidity were delayed.

\section{Methods}

\subsection{Data Collection}

This study was conducted in Campo Grande, Brazil. Campo Grande city $\left(20^{\circ} 27^{\prime} 16^{\prime \prime} \mathrm{S}\right.$; 54 47 $47^{\prime} 16^{\prime \prime} \mathrm{W}$, altitude 650 $\mathrm{m}$ ) is sited on the Maracaju-Campo Grande plateau. The region is tropical with high temperatures predominating throughout the year. It has high rainfall and high relative humidity (Sant' Anna Neto et al., 2003).

We obtained data on health centers' records of out-patient visits from the Secretary for Municipal Health from January 2008 to 31 December 2011. Respiratory diseases were coded using the $9^{\text {th }}$ Revised International Classification of Diseases (ICD-9: 460 to 519). We also stratified the respiratory morbidity by age $(0-4,5-60$, and $>60$ years).

We obtained the daily mean ozone concentration $\left(\mathrm{O}_{3}\right.$ in ppb) from 2008 to 2011 . The ozone pollution was measured at the monitoring station of the Physics Department of the Federal University of Mato Grosso do Sul. Ozone concentrations were recorded every 15 minutes, which were used to calculate daily mean concentrations.

We collected daily data on mean temperature, relative humidity from the EMPRAPA research station for beef production in Campo Grande.

\subsection{Data Analysis}

A quasi-Poisson regression model with distributed lag non-linear model (DLNM) was used to examine the effects of ozone on morbidity. The quasi-Poisson function has the ability to adjust inference for overdispersion [16].

The DLNM allows nonlinear function for exposure and lag to be modeled simultaneously in quite flexible ways [17] [18]. To examine the non-linear ozone-morbidity relationship, a DLNM was used for ozone with 5 degrees of freedom natural cubic spline, and 4 degrees of freedom natural cubic spline was used for lag up to 6 days. We controlled for temperature and relative humidity using a DLNM with 5 degrees of freedom natural cubic spline for exposure (mean temperature and relative humidity) and 4 degrees of freedom natural cubic spline for lag up to 10 days. We controlled for day of the week using category variable. We controlled for seasonality and long-term trend using natural cubic spline with 7 degrees of freedom per year for time.

\section{Results}

There were 26,941 respiratory hospital admissions during the study period. The daily average concentrations of 
$\mathrm{O}_{3}$ were below the quality standards of ozone pollution $(80 \mathrm{ppb})$ (Table 1$)$. The average counts of daily admissions for respiratory diseases were: total admissions for respiratory diseases (11), 0 - 4 years of (5), 5 - 60 years (3), and $>60$ years (3) (Table 1 ).

Figure 1 shows the time series of respiratory hospital admission, ozone and mean temperature. $\mathrm{O}_{3}$ had a seasonal trend, with higher concentration in summer than winter. Respiratory hospital admissions were higher in winter than summer.

Figure 2 shows the relationship between ozone and respiratory hospital admission at lag 0 - 6 days. We found that the effects of ozone on respiratory hospital admission were non-linear, with a threshold at $13 \mathrm{ppb}$. The effects of ozone on children and the elderly were high than people aged 5 - 60 years.

Table 2 shows the estimated relative risks (RR) corresponds to age group: all year risk with interval $\mathrm{RR}=$ 1.1079; CI: (1.0379 - 1.1826); risk of 0 - 4 years with a range of RR $=1.1296$; CI: $(1.0524-1.2125), 5-60$ years, risk with interval of $R R=1.014$; CI: (0.9410 - 1.0928) and $>60$ years with risk interval and 1.1546 (1.0406 and 1.2811).

Table 2 and Figure 3 show the relative risks of hospital admissions at $75 \%$ percentile of ozone distribution compared with $25 \%$ percentile along the lag days. Results show that the effects on hospitalizations were delayed by two days, and lasted for four days.

\section{Discussion}

The purpose of this study was to examine the effects of ozone on respiratory hospital admissions in Campo Grande, Brazil during 2008-2011. We found that the ozone-respiratory morbidity relationship was non-linear. The effects of ozone on respiratory morbidity were delayed by two days and lasted for 4 days for all age groups except people aged 5 - 60 years. Children and the elderly were much more vulnerable to ozone pollution than people aged 5 - 60 years.

The magnitude of the association ozone pollution and hospital admissions for respiratory disease was similar to studies conducted in San Paulo [2]-[4]. This might be caused by that the source of zone pollutant in the city is almost the same: the mobile sources, mainly, and stationary sources (industries) and biomass burning in Campo

Table 1. Descriptive analysis of respiratory hospital admission, ozone, and weather conditions in Campo Grande, Brazil during 2008-2011.

\begin{tabular}{cccccccc}
\hline & Average & $\begin{array}{c}\text { Standard } \\
\text { deviation }\end{array}$ & Minimum & 10 quartil & Median & 30 quartil & Maximum \\
\hline Total & 11 & 3 & 2.00 & 8.00 & 10.00 & 12.00 & 23.00 \\
0 - 4 years & 5 & 2 & 1.00 & 4.00 & 5.00 & 6.00 & 13.00 \\
5 - 60 years & 3 & 1 & 0.00 & 2.00 & 2.00 & 3.00 & 8.00 \\
$>60$ years & 3 & 1 & 0.00 & 2.00 & 3.00 & 3.00 & 7.00 \\
Ozono (ppb) & 17.56 & 8 & 0.66 & 12.97 & 16.44 & 20.73 & 52.76 \\
Mean Temperature $\left({ }^{\circ} \mathrm{C}\right)$ & 23.50 & 4 & 7.00 & 22.10 & 24.20 & 25.73 & 30.81 \\
Relative humidity $(\%)$ & 66.06 & 16.12 & 19.16 & 55.00 & 67.81 & 78.83 & 98.00 \\
\hline
\end{tabular}

Table 2. Relative risk (RR) of respiratory hospital admissions at at $75 \%$ percentile of ozone distribution compared with $25 \%$ percentile along the lag days in Campo Grande, Brazil during 2008-2011.

\begin{tabular}{ccccc}
\hline & All years & $0-4$ years & 5 - 60 years & P60 years \\
\hline & RR-CI & RR-CI & RR-CI & RR-CI \\
\hline lag 0 & $1.0035 ;(0.9758-1.0321)$ & $1.0153 ;(0.9850-1.0466)$ & $0.9775 ;(0.9465-1.0095)$ & $1.0028 ;(0.9587-1.0488)$ \\
lag 1 & $1.0128 ;(0.9989-1.0270)$ & $1.0191 ;(1.0039-1.0345)$ & $0.9921 ;(0.9764-1.0080)$ & $1.0188 ;(0.9965-1.0416)$ \\
lag 2 & $1.0119 ;(1.0046-1.0336)$ & $1.0211 ;(1.0056-1.0369)$ & $1.0031 ;(0.9868-1.0196)$ & $1.0292 ;(1.0061-1.0530)$ \\
lag 3 & $1.0209 ;(1.0056-1.0365)$ & $1.0209 ;(1.0043-1.0376)$ & $1.0092 ;(0.9918-1.0269)$ & $1.0320 ;(1.0073-1.0573)$ \\
lag 4 & $1.0196 ;(1.0068-1.0325)$ & $1.0189 ;(1.0051-1.0328)$ & $1.0115 ;(0.9970-1.0263)$ & $1.0287 ;(1.0082-1.0496)$ \\
lag 5 & $1.0160 ;(1.0021-1.0302)$ & $1.0157 ;(1.0006-1.0310)$ & $1.0113 ;(0.9954-1.0274)$ & $1.0215 ;(0.9992-1.0444)$ \\
lag 6 & $1.0114 ;(0.9883-1.0352)$ & $1.0120 ;(0.9870-1.0376)$ & $1.0097 ;(0.9832-1.0369)$ & $1.0125 ;(0.9754-1.0509)$ \\
\hline
\end{tabular}



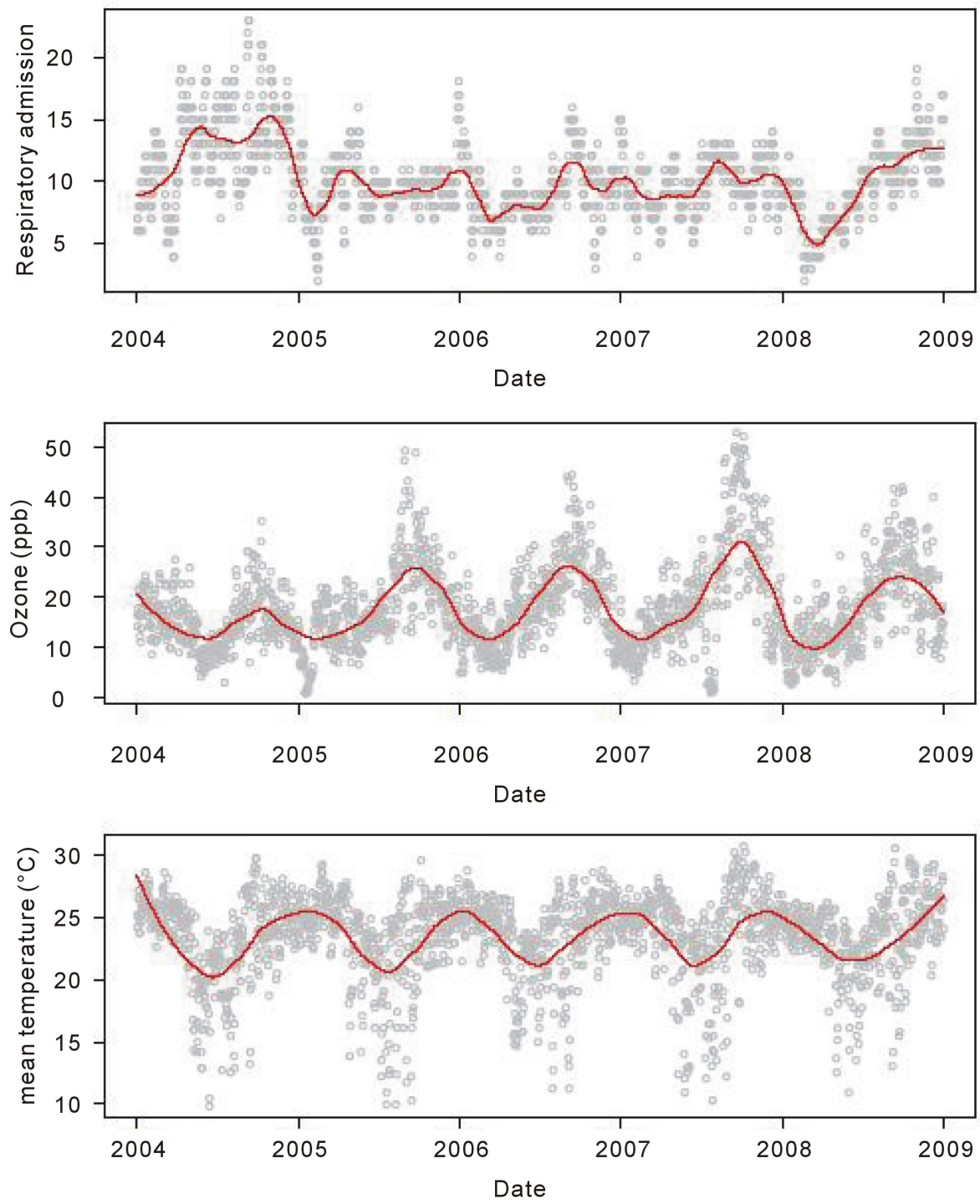

Figure 1. Time series of respiratory hospital admissions, ozone concentration (ppb) and mean temperature $\left({ }^{\circ} \mathrm{C}\right)$ during 2008-2011.

Grande.

Ozone-related epidemiological studies generally assume a linear effect of ozone [19]. However, Lefohn et al. reported a nonlinear relationship between ozone dose and pulmonary function [20]. The lag effect of air pollutants is also considered a critical factor in health assessments. This study applied DLNM to calculate the nonlinear association and cumulative risks across lag days for air pollutants. The findings enable greater flexibility when presenting the nonlinear ozone exposure-response curve for outpatient visits for total respiratory diseases (RD).

We found that children and the elderly were much more sensitive to ozone pollution than adult. Children are highly susceptible to exposure to air pollutants. Minute ventilation is higher in children than that in adults because children have higher basal metabolic rates and engage in more physical activity than adults do, as well as because children spend more time outdoors than adults do. On the basis of body weight, the volume of air passing through the airways of a child at rest is twice that of an adult under similar conditions. Pollutant-induced irritation producing a weak response in adults can result in significant obstruction in children. In addition, the fact that their immune system is not fully developed increases the possibility of respiratory infections [21] [22].

Elderly individuals are susceptible to the adverse effects of exposure to air pollutants because they have a less 

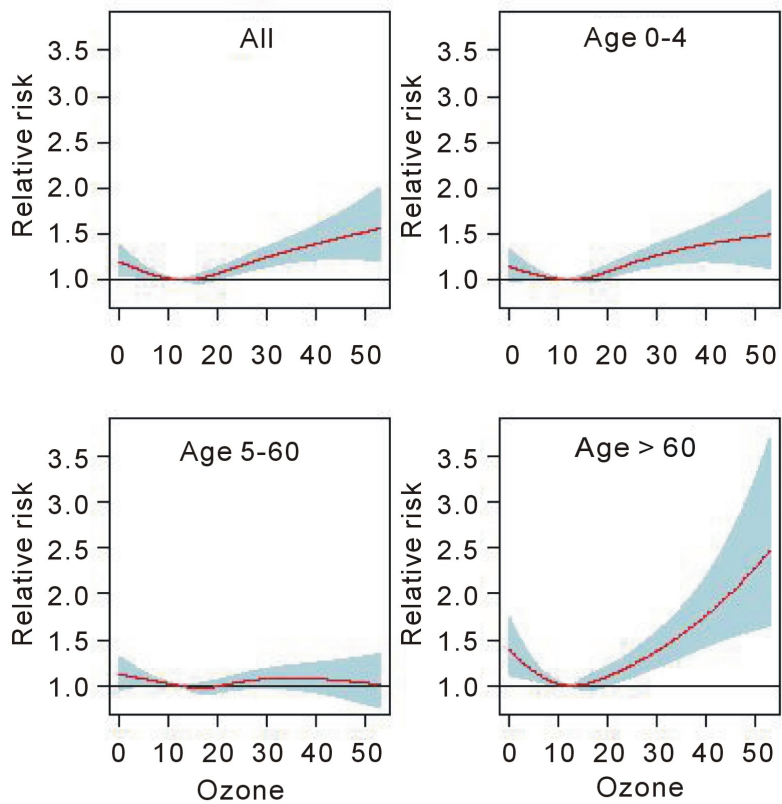

Figure 2. Relationship between ozone and respiratory hospital admission in Campo Grande, Brazil during 2008-2011.
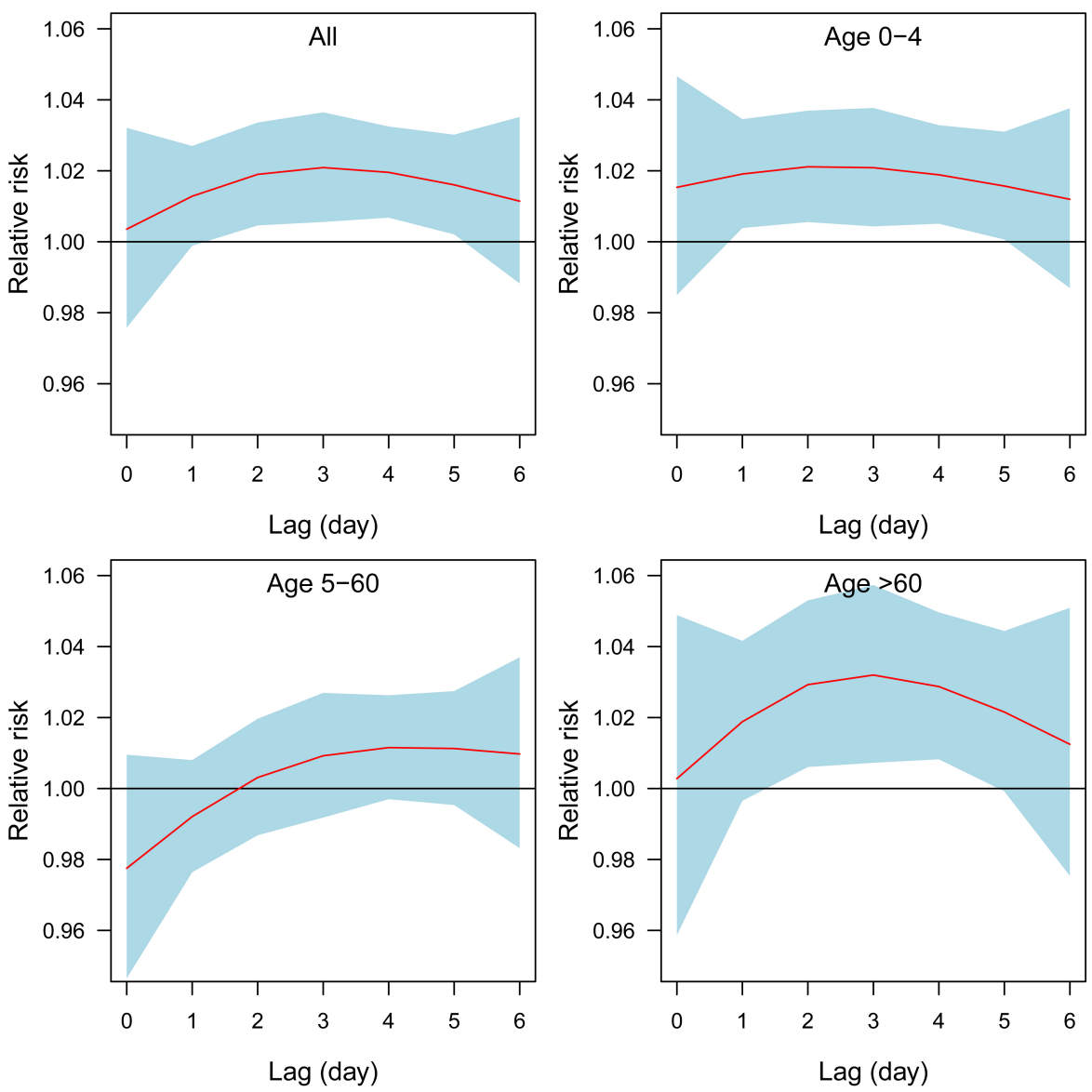

Figure 3. Relative risk of respiratory hospitalizations at $75 \%$ percentile of ozone distribution compared with 25\% percentile along the lag days in Campo Grande, Brazil during 2008-2011. 
efficient immune system (immunosenescence) and a progressive decline in pulmonary function that can lead to airway obstruction and exercise limitation. There is decreased chest wall compliance and lung hyperinflation requiring additional energy expenditure to perform respiratory movements, as well as functional decline of organ systems [23] [24].

Several mechanisms have been suggested to explain the adverse effects of air pollutants. The most consistent and most widely accepted explanation is that, once in contact with the respiratory epithelium, high concentrations of oxidants and pro-oxidants in environmental pollutants such as PM of various sizes and compositions and in gases such as $\mathrm{O}_{3}$ and nitrogen oxides cause the formation of oxygen and nitrogen free radicals, which in turn induce oxidative stress in the airways. In other words, an increase in free radicals that are not neutralized by antioxidant defenses initiates an inflammatory response with release of inflammatory cells and mediators (cytokines, chemokines, and adhesion molecules) that reach the systemic circulation, leading to subclinical inflammation, which not only has a negative effect on the respiratory system but also causes systemic effects [21].

\section{References}

[1] UNFPA - United Nations Population Fund (2012) State of World Population 2011. http://www.unfpa.org/swp/

[2] Braga, A.L.F., Conceição, G.M.S., Pereira, L.A.A., Kihi, H.S., Pereira, J.C.R., Andrade, M.F., et al. (1999) Air Pollution and Pediatric Respiratory Hospital Admissions in São Paulo, Brazil. Journal of Environmental Medicine, 2, 95-102. http://dx.doi.org/10.1002/(SICI)1099-1301(199904/06)1:2<95::AID-JEM16>3.0.CO;2-S

[3] Braga, A.L.F., Saldiva, P.H.N., Pereira, L.A.A., Menezes, J.J.C., Conceição, G.M.S., Lin, C.A., et al. (2001) Health Effects of Air Pollution Exposure on Children and Adolescents in São Paulo, Brazil. Pediatric Pulmonology, 31, 106-113. http://dx.doi.org/10.1002/1099-0496(200102)31:2<106::AID-PPUL1017>3.0.CO;2-M

[4] Lin, A.C., Martins, M.A., Farhat, S.L., Pope III, C.A., Conceição, G.M.S., Anastácio, M.V., et al. (1999) Air Pollution and Respiratory Illness of Children in São Paulo, Brazil. Paediatric and Perinatal Epidemiology, 13, 475-488. http://dx.doi.org/10.1046/j.1365-3016.1999.00210.x

[5] Atkinson, R.W., Anderson, H.R., Sunyer, J., Ayres, J., Baccini, M., Vonk, J.M., et al. (2001) Acute Effects of Particulate Air Pollution on Respiratory Admission: Results from APHEA 2 Project. Air Pollution and Health: A European Approach. American Journal of Respiratory and Critical Care Medicine, 164, 1860-1866. http://dx.doi.org/10.1164/ajrccm.164.10.2010138

[6] Martins, L.C., Latorre, M.R.D.O., Cardoso, M.R.A., Gonçalves, F.L.T., Saldiva, P.H.N. and Braga, A.L.F. (2002) Poluição atmosférica e atendimentos por pneumonia e gripe em São Paulo, Brasil. Revista de Saúde Pública, 36, 88-94. http://dx.doi.org/10.1590/S0034-89102002000100014

[7] Schwartz, J. and Marcus, A. (1990) Mortality and Air Pollution in London: A Time Series Analysis. American Journal of Epidemiology, 131, 185-194.

[8] Schwartz, J. and Dockery, D.W. (1992) Particulate Air Pollution and Daily Mortality in Steubenville, Ohio. American Journal of Epidemiology, 135, 12-19.

[9] World Health Organization (2009) Health Risks of Ozone from Long-Range Transboundary Air Pollution. WHO Regional Office for Europe, Copenhagen.

[10] World Health Organization (2005) Air Quality Guidelines. Global Update 2005. Particulate Matter, Ozone, Nitrogen Dioxide and Sulfur Dioxide. World Health Organization, Copenhagen.

[11] Schwartz, J. (2004) Air Pollution and Children's Health. Pediatrics, 113, 1037-1043.

[12] Schwartz, J. (2000) Harvesting and Long Term Exposure Effects in the Relation between Air Pollution and Mortality. American Journal of Epidemiology, 151, 440-448. http://dx.doi.org/10.1093/oxfordjournals.aje.a010228

[13] Koren, H.S. (1995) Associations between Criteria Air Pollutants and Asthma. Environmental Health Perspectives, 103, 235-242. http://dx.doi.org/10.1289/ehp.95103s6235

[14] Fusco, D., Forastiere, F., Michelozzi, P., Spadea, T., Ostro, B., Arcà, M. and Perucci, C.A. (2001) Air Pollution and Hospital Admissions for Respiratory Conditions in Rome, Italy. European Respiratory Journal, 17, 1143-1150. http://dx.doi.org/10.1183/09031936.01.00005501

[15] Galán, I., Tobías, A., Banegas, J.R. and Aránguez, E. (2003) Short-Term Effects of Air Pollution on Daily Asthma Emergency Room Admissions. European Respiratory Journal, 22, 802-808. http://dx.doi.org/10.1183/09031936.03.00013003

[16] Sant'Anna Neto, J.L. and da. Anunciação, V.S. (2003) Uma reflexão do espaço urbano da cidade de Campo Grande/ MS na perspectiva climática. Rev. Pantaneira, 3.

[17] Hardin, J. and Hilbe, J. (2011) Generalized Linear Models and Extensions. Stata Corporation, College Station. 
[18] Gasparrini, A. andArmstrong, B. (2010) DLNM: Distributed Lag Non-Linear Models, R Package Version 1.2.4. The Comprehensive R Archive Network, Vienna.

[19] Gasparrini, A., Armstrong, B., Kenward, M.G. (2010) Distributed Lag Non-Linear Models. Statistics in Medicine, 29, 2224-2234. http://dx.doi.org/10.1002/sim.3940

[20] Bell, M.L., Dominici, F. and Samet, J.M. (2005) A Meta-Analysis of Time-Series Studies of Ozone and Mortality with Comparison to the National Morbidity, Mortality, and Air Pollution Study. Epidemiology, 16, 436-445. http://dx.doi.org/10.1097/01.ede.0000165817.40152.85

[21] Lefohn, A.S., Hazucha, M.J., Shadwick, D. and Adams, W.C. (2010) An Alternative Form and Level of the Human Health Ozone Standard. Inhalation Toxicology, 22, 999-1011. http://dx.doi.org/10.3109/08958378.2010.505253

[22] Künzli, N., Perez, L. and Rapp, R. (2010) Air Quality and Health. European Respiratory Society, Lausanne.

[23] Salvi, S. (2007) Health Effects of Ambient Air Pollution in Children. Paediatric Respiratory Reviews, 8, $275-280$. http://dx.doi.org/10.1016/j.prrv.2007.08.008

[24] Sharma, G. and Goodwin, J. (2006) Effect of Aging on Respiratory System Physiology and Immunology. Journal of Clinical Interventions in Aging, 1, 253-260. http://dx.doi.org/10.2147/ciia.2006.1.3.253 